\title{
How frequently are physiological variables recorded in the emergency room in patients with obstructive pulmonary diseases and pneumonia?
}

\author{
Lars K Hægstad ${ }^{a}$, Torbjørn Bjotveit' ${ }^{\mathrm{a}}$, Ane Johannessen ${ }^{\mathrm{b}}$, *Amund Gulsvik ${ }^{\mathrm{a}}$ \\ a Section of Thoracic Medicine, Institute of Medicine, University of Bergen, Norway \\ ${ }^{\mathrm{b}}$ Centre for Clinical Research, Haukeland University Hospital, Norway
}

Received 3rd December 2007; revised 7th March 2008; accepted 6th July 2008; online 2nd October 2008

\begin{abstract}
Aim: To assess how frequently measurements of relevant physiological variables are made in patients presenting acutely to hospital with obstructive pulmonary diseases (OPD) and pneumonia.

Methods: Patients admitted to three hospitals in western Norway with OPD (asthma or chronic obstructive pulmonary disease (COPD)) and/or pneumonia over a 75-day period were included in the study. The assessing physicians in the emergency room (ER) were asked to measure and record physiological variables according to normal practice.

Results: There were 338 patients (54\% women), with an average age of 64 (SD 19) years. The initial diagnoses were OPD (176), pneumonia (103) and a combination of OPD and pneumonia (59). Heart rate and body temperature were recorded in almost all patients, whereas the recording of all other variables varied from $45 \%$ to $91 \%$. Most variables were recorded more frequently in OPD than in pneumonia.

Conclusions: The importance of recording respiratory rate, cutaneous oxygen saturation, and peak expiratory flow should be stressed in the training of physicians.

(C) 2009 General Practice Airways Group. All rights reserved.

LK Hægstad et al. Prim Care Resp J 2009; 18(2): 95-99.

doi:10.3132/pcrj.2008.00057
\end{abstract}

Keywords asthma, COPD, pneumonia, statistics, hospital, medical education

\section{Introduction}

In textbooks of medicine there is no agreement on which physiological variables should be recorded in patients with suspected chronic obstructive pulmonary disease (COPD) and pneumonia. ${ }^{1-6}$ When acute lung diseases are suspected, physicians frequently measure respiratory rate, heart rate, body temperature and blood pressure. ${ }^{7.8} \mathrm{~A}$ simple method of assessing lung function in the emergency room (ER) is measurement of peak expiratory flow (PEF), ${ }^{9}$ cutaneous oxygen saturation ${ }^{10} \mathrm{and} / \mathrm{or}$ arterial blood gas concentrations. ${ }^{11}$ Measurement of $\mathrm{C}$-reactive protein (CRP) may be of value when deciding whether or not a patient presenting with infection should be treated with antibiotics. ${ }^{12,13}$ To our knowledge there is no information on how often physiological variables are measured and recorded in the ER, and what distinguishes the recordings in OPD from the ones in pneumonia.

The aim of this study was to estimate how frequently respiratory rate, heart rate, body temperature, PEF, cutaneous oxygen saturation, arterial blood gas concentrations, and CRP were recorded in patients admitted to hospital with OPD and/or pneumonia. We wished to establish whether the recording of these variables was associated with the patients' sex, age, initial diagnosis and/or severity of disease.

\section{Methods}

All patients admitted with OPD and pneumonia to the Haugesund County Hospital, Haraldsplass Deaconal Hospital

* Corresponding author: Institute of Medicine, University of Bergen, Jonas Liesvei 65, 5021 Bergen, Norway

Tel: +4755973242 E-mail: amund.gulsvik@med.uib.no 
and Haukeland University Hospital were registered between April 1 to June 15 1997. ${ }^{14-16}$ The hospital district of Bergen, with Haraldsplass Deaconal Hospital and Haukeland University Hospital, covers 15 municipalities with a total catchment area of 251,936 citizens aged over 15. The Haugesund hospital district, with Haugesund County Hospital, encompasses eleven municipalities with a catchment area of 77,337 citizens aged over $15 .{ }^{17}$

In total, 438 patients were admitted with a diagnosis of OPD and/or pneumonia. Physicians and nurses in the ER measured and recorded variables according to normal practice. In addition the physician on duty filled in a registration form for each patient. The form had been tested in a pilot scheme. The patient's age, sex, initial diagnosis and disease severity were recorded. Each receiving physician was asked to classify the patient according to disease severity (i.e. mild, moderate, serious/life threatening) to the best of his or her judgement. There were no demands for objective measurements in order to estimate disease severity - i.e. every physician assessed disease severity based on experience, education and normal hospital routine. The initial diagnosis was made by the referring physician or by the receiving physician if there was no referred diagnosis. The patients were diagnosed with OPD (COPD and asthma), pneumonia or a combination of OPD and pneumonia.

Data were obtained on the frequency of recording of respiratory rate (/minute), peripheral heart rate (/minute), PEF (L/minute), body temperature $\left({ }^{\circ} \mathrm{C}\right)$, cutaneous oxygen saturation (\%), arterial blood gas concentration (arterial oxygen $\left(\mathrm{PaO}_{2}\right)$ and carbon dioxide tension $\left.\left(\mathrm{PaCO}_{2}\right)(\mathrm{kPa})\right)$, and CRP (mg/L).

Heart rate and body temperature were measured by nurses. Respiratory rate was recorded by physicians. Measurement of PEF was conducted by physicians or nurses by means of a simple, portable peak flow meter. The physicians were responsible for measuring CRP and cutaneous oxygen saturation, and obtained blood samples for arterial blood gas analysis; cutaneous oxygen saturation was measured by nurses when asked by physicians, and the patient's venous CRP level was analysed at the local medical biochemistry laboratory.

The registration form was filled in by 26 physicians who were on primary duty at the three hospitals, and 110 nurses measured heart rate, body temperature and cutaneous oxygen saturation. The median number of registered patients per physician was 11 (range 1-23). The data were coded in SPSS ("Statistical Product and Service Solutions) 7.5 for Windows. ${ }^{15}$

\section{Statistical analyses}

All statistical analyses were performed using SPSS 13.0 for Windows. Pearson's Chi-square test was used to investigate possible associations between the initial diagnosis and the patients' age, sex and disease severity. We also investigated any association between initial diagnosis and registration of heart rate, body temperature, respiratory rate, PEF, cutaneous oxygen saturation, arterial blood gas concentrations, and CRP by means of Pearson's Chi-square test. Odds ratios with $95 \%$ confidence interval were calculated by multiple logistic regression for how frequently these variables were registered depending on sex, age, initial diagnosis and disease severity. The level of significance for all analyses was set at 0.05 .

\section{Results}

\section{Sex, age, diagnosis and disease severity}

The study population was 338 patients $(77 \%$ of those admitted in the timeframe) with either OPD (176 patients), pneumonia (103 patients), or a combination of the two (59 patients) - see Table 1. Two hundred and twenty-six patients (67\%) were admitted to Haukeland University Hospital, 27 (8\%) to Haraldsplass Deaconal Hospital and 85 (25\%) to Haugesund County Hospital. The average age (SD) was 64 (19), and 54\% were women. The patients' ages were, as expected, unevenly distributed, with the median age being 71 years (range 14 - 93 years). There were no differences in age between the sexes and diagnostic groups. Women (63\%) were admitted for OPD more frequently than men, while the combination of OPD and pneumonia was a more frequent diagnosis amongst men (64\%) (both $\mathrm{p}<0.001)$. The condition was classified as being mild, moderate or serious/life threatening in 84, 163 and 90 patients, respectively. A higher proportion of patients with pneumonia were classified as being more severely ill (moderate, serious/life threatening) compared to those with OPD ( $82 \%$ versus $69 \%$; $p<0.05$ ). There was no significant association between the patient's age and the initial diagnosis ( $p=0.321)$.

\section{Recording of variables}

Heart rate, body temperature and CRP were recorded in almost all patients - i.e. in 99\%, 97\% and 91\%, respectively (see Table 2). Arterial blood gas concentrations were recorded in $78 \%$, respiratory rate in $66 \%$, PEF in $49 \%$, and cutaneous oxygen saturation in $45 \%$ of patients. Arterial blood gas concentrations were recorded more frequently in men $(84 \%)$ than in women $(75 \%)(p<0.05)$.

Measurement of PEF was performed in two-thirds of the patients with OPD, in approximately half of the patients with a combination diagnosis of OPD and pneumonia, but only in one-sixth of the patients with pneumonia $(p<0.001)$. Measurements of respiratory rate, PEF, arterial blood gas concentration and cutaneous oxygen saturation were all associated with the initial diagnosis $(p<0.001)$ - Table 2 . Cutaneous oxygen saturation was more frequently recorded in patients with OPD and concurrent pneumonia than in 
Table 1. Age, sex and disease severity in 338 patients presenting with obstructive pulmonary disease, pneumonia or a combination of obstructive pulmonary disease and pneumonia.

\begin{tabular}{|c|c|c|c|c|c|}
\hline & $\begin{array}{l}\text { Obstructive pulmonary } \\
\text { disease }\end{array}$ & Pneumonia & $\begin{array}{l}\text { Obstructive pulmonary } \\
\text { disease and pneumonia }\end{array}$ & All & p-value* \\
\hline $\mathrm{N}$ & 176 & 103 & 59 & 338 & \\
\hline Age, average (SD) ; years & $63(19)$ & $63(20)$ & $66(17)$ & $64(19)$ & 0.321 \\
\hline \multicolumn{6}{|l|}{ Sex; } \\
\hline Women; \% & 63 & 50 & 36 & 54 & 0.001 \\
\hline Men; \% & 37 & 50 & 64 & 46 & \\
\hline \multicolumn{6}{|l|}{ Disease severity; } \\
\hline Mild; \% & 31 & 18 & 17 & 25 & \\
\hline Moderate; \% & 42 & 52 & 62 & 48 & 0.026 \\
\hline Serious/life treatening; \% & 27 & 30 & 21 & 27 & \\
\hline
\end{tabular}

Table 2. Total number and percentage of patients in whom respiratory rate, heart rate, body temperature, peak expiratory flow, cutaneous oxygen saturation, arterial oxygen tension, arterial carbon dioxide tension and venous C-reactive protein were recorded by diagnosis.

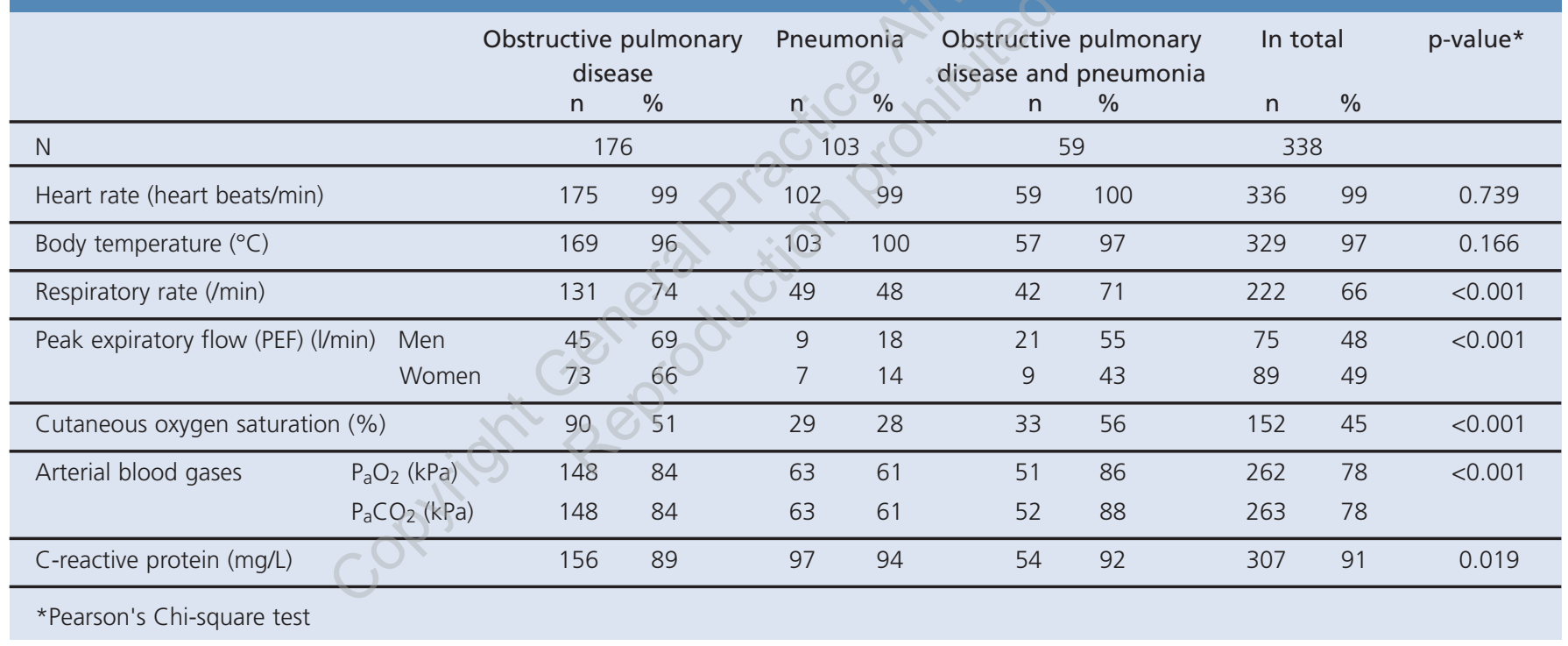

patients who only had pneumonia $(p<0.001)$.

Arterial blood gas concentrations were recorded less frequently in patients below the age of $45(66 \%)$ than in patients aged 65 to 79 years (82\%), and most frequently in patients older than 80 years $(93 \%)(p<0.001)$. Arterial blood gas concentrations were recorded in almost nine out of 10 patients with OPD or OPD and pneumonia, but only in two out of three patients with pneumonia $(p<0.001)$. CRP was recorded more frequently when the initial diagnosis was pneumonia than when the initial diagnosis was OPD $(p<0.05)$.

Peak expiratory flow and respiratory rate were far more frequently recorded in patients admitted to Haukeland University Hospital (58\% and $72 \%$, respectively) than in patients admitted to the other two hospitals (30\% and $58 \%$, respectively; $p<0.01)$. CRP was more frequently recorded in Haugesund County Hospital and Haraldsplass Deaconal Hospital (94\% of patients) than in Haukeland University Hospital $(90 \%)(p<0.05)$

\section{Multivariate analyses}

In a multiple logistic regression adjusted for sex, age, diagnosis and disease severity we found that respiratory rate, PEF, cutaneous oxygen saturation and arterial blood gas concentrations were less frequently recorded in patients with pneumonia than in patients with OPD (Table 3). Cutaneous oxygen saturation and arterial blood gas concentrations were, as expected, more frequently measured in patients with serious or life threatening disease, whereas respiratory rate and PEF seemed to be recorded independently of disease 
Table 3. Odds ratio $(95 \% \mathrm{Cl})$ for the registration of respiratory rate, peak expiratory flow, cutaneous oxygen saturation and arterial blood gases adjusted for sex, age, diagnosis and disease severity, $\mathrm{n}=338$

\begin{tabular}{|c|c|c|c|c|}
\hline & $\begin{array}{l}\text { Respiratory } \\
\text { rate }\end{array}$ & $\begin{array}{l}\text { Peak expiratory } \\
\text { flow }\end{array}$ & $\begin{array}{l}\text { Cutaneous oxygen } \\
\text { saturation }\end{array}$ & $\begin{array}{l}\text { Arterial blood } \\
\text { gases }\end{array}$ \\
\hline \multicolumn{5}{|l|}{ Sex: } \\
\hline Man & 1.0 & 1.0 & 1.0 & 1.0 \\
\hline Woman & $0.9(0.5,1.4)$ & $0.8(0.5,1.3)$ & $1.1(0.7,1.8)$ & $0.5(0.3,1.0)$ \\
\hline \multicolumn{5}{|l|}{ Age: } \\
\hline$<65$ years & 1.0 & 1.0 & 1.0 & 1.0 \\
\hline$\geq 65$ years & $1.3(0.8,2.1)$ & $0.7(0.4,1.1)$ & $1.0(0.6,1.6)$ & $2.7(1.5,4.8)$ \\
\hline \multicolumn{5}{|l|}{ Diagnosis: } \\
\hline Obstructive pulmonary disease & 1.0 & 1.0 & 1.0 & 1.0 \\
\hline Pneumonia & $0.3(0.2,0.5)$ & $0.1(0.0,0.2)$ & $0.3(0.2,0.6)$ & $0.2(0.1,0.5)$ \\
\hline $\begin{array}{l}\text { Combination of obstructive pulmonary } \\
\text { disease and pneumonia }\end{array}$ & $0.8(0.4,1.5)$ & $0.5(0.3,1.0)$ & $1.2(0.6,2.2)$ & $1.0(0.4,2.6)$ \\
\hline \multicolumn{5}{|l|}{ Disease severity: } \\
\hline Mild & 1.0 & 1.0 & 1.0 & 1.0 \\
\hline Moderate & $1.1(0.6,2.0)$ & $0.9(0.5,1.7)$ & $1.7(0.9,3.0)$ & $1.8(0.9,3.5)$ \\
\hline Serious/life threatening & $1.2(0,6,2,2)$ & $0.6(0.3,1.3)$ & $3.5(1.8,6.7)$ & $6.3(2.5,16.0)$ \\
\hline
\end{tabular}

severity and age. Measurement of arterial blood gas concentration was performed almost three times more frequently in patients aged over 65 years than in younger patients. There were no differences between the sexes as regards the recording of respiratory rate, PEF, cutaneous oxygen saturation and arterial blood gas concentrations.

\section{Discussion}

Heart rate and body temperature were recorded in almost all patients, CRP recorded in $91 \%$ of patients, whereas the other variables were recorded in between $45 \%$ to $71 \%$ of patients. The least frequently recorded variables were cutaneous oxygen saturation and PEF. Respiratory rate, PEF, cutaneous oxygen saturation and arterial blood gas concentrations were recorded more often in patients presenting with possible OPD than in patients presenting with possible pneumonia, whereas CRP was recorded more frequently when pneumonia was suspected. Arterial blood gas concentrations were recorded more frequently in seriously ill patients and in the elderly. It is worth noting that measurements made by nurses were more often recorded than measurements made or requested by physicians. A more intensive investigative regime was applied to those with more serious disease.

The strength of this study is that we have data from a large number of patients with OPD and pneumonia admitted to three hospitals in western Norway. Participation in the study was high (77\%). Several hospital physicians took part, and our findings should therefore reflect ER contemporary practice in Norway.

A weakness of this study might be that physicians had to fill in a registration/recording form, thus leading to improved recording rates of physiological variables compared to when a form was not available. Without this reminder, it is possible that the number of performed tests and measurements would have been lower. Future studies ought also to include the frequency of chest $X$-ray and blood culture requests as well as recording rates for blood pressure and, in particular, spirometry measurements which can be used to rule out airway obstruction in hospitalised patients. ${ }^{18}$ Spirometry is also a widely recognised means of assessing COPD severity. ${ }^{19}$

Optimal treatment and correct intensive care of acute pulmonary disease demands knowledge of the levels of several physiological variables. The categorisation of asthma and COPD into mild, moderate or serious/life threatening presentations is defined by the levels of heart rate, respiratory rate, arterial blood gas concentrations and PEF. ${ }^{19,20}$ Our study shows that physicians in the ER do not apply these variables systematically when discerning mild, moderate and serious/ life threatening disease. The physicians' assessment of disease severity is possibly strongly influenced by the patients' fear and dyspnoea, and to a lesser degree by the values of the recorded physiological variables. More complete recording of these variables should be sought.

The highest frequency of recording was observed for body temperature, heart rate, and CRP, where the measurements were performed by nurses or bioengineers, not by physicians. Respiratory rate is a central predictor for estimating disease severity in pulmonary disease. ${ }^{6}$ The poor rate of recording of this variable and the PEF might come from a lack of emphasis on these variables in the training of physicians, or insufficient routine in medical examination in hospitals. Cutaneous oxygen saturation was recorded in less than half of the patients presenting with acute pulmonary disease. This simple and 
inexpensive test should be used more frequently. Measurement of arterial blood gas concentrations ought to be required only when cutaneous oxygen saturation is lower than $90 \%,{ }^{21}$ or if hypoventilation is suspected. However, arterial blood gas analysis is indicated for patients presenting in the ER with acute exacerbations of COPD; spirometric criteria cannot eliminate the need for arterial blood gas analysis in COPD patients because they can't identify patients with significant hypoxemia.22 Thus, the NICE Guideline recommends arterial blood gas analysis in patients admitted to hospital presenting with acute exacerbations of COPD. ${ }^{23}$ Moreover, in order to distinguish between cardiac and pulmonary dyspnoea, measurements of $\mathrm{PEF}, \mathrm{P}_{2} \mathrm{O}_{2}, \mathrm{P}_{2} \mathrm{CO}_{2}$ and indices of these variables are necessary tools in the ER. ${ }^{24}$ The percentage of OPD patients who had arterial blood gas concentrations measured in our study (84\%) is considerably higher than the recording rate of $64 \%$ in 70,000 patients admitted to hospital with acute exacerbations of COPD in the USA. ${ }^{25}$

Several papers ${ }^{26,27}$ indicate that physicians often fail to use spirometry for routine monitoring of asthma and COPD. Our study shows a similar failure in the use of PEF, which was measured and recorded in only two-thirds of patients admitted to hospital with acute exacerbations of OPD. PEF is a reproducible and reliable test, and can be helpful in the dayto-day management of patients with known COPD. ${ }^{28}$

This study has shown that there is considerable potential for improving the management of patients admitted to hospital with acute pulmonary diseases - in particular, more complete recording of physiological variables in the ER. Measures to improve management include: improved education of medical students and physicians; increased competence amongst other health personnel; and development of appropriate and easy-to-use computer programmes for regular analysis and reporting.

\section{Conflicts of interest}

None declared.

\section{Acknowledgements}

We thank Odd Mørkve, MD PhD, Department of Medicine Haraldsplass Deaconal Hospital, and Knut Skaug, MD, Department of Thoracic Medicine Haugesund Hospital, for assistance in the collection of data.

\section{References}

1. Camm AJ, Bunce NH. Cardiovascular Disease. Frew AJ, Holgate ST. Respiratory Disease. In: ed. Kumar P, Clark M. Clinical Medicine, Fifth Edition.Saunders, 2002. p. $865,880,883,891$.

2. Haslett C, Chilvers E, Corris PA. Respiratory Diseases. In: Haslett C, Chilvers E, Boon N, ed. Davidson's Practice and Principles of Medicine, 19th edition. Churchill Livingstone 2002. p.483-574.

3. Souhami RL, Moxham J. Textbook of medicine, Fourth edition. Churchill Livingstone 2002. p.611, 620, 655, 658, 663.

4. Ledingham JGG, Warrell DA. Concise Oxford Textbook of Medicine. Oxford University Press, 2000. p.373, 394, 395, 419.

5. Hunskår S (red.). Allmennmedisin, 2. utgave. Gyldendal Norsk Forlag AS 2003. p. $461-3,465,467$
6. Gulsvik A og Bakke PS. Lungesykdommer - en basal innføring. Fagbokforlaget Vigmostad og Bjørke, 2004. p.87, 120, 121, 135, 136.

7. Rodrigo GJ, Rodrigo C, Hall JB. Acute asthma in adults: a review. Chest 2004;125:1081-102. http://dx.doi.org/10.1378/chest.125.3.1081

8. Rhew DC, Weingarten SR. Achieving a safe and early discharge for patients with community-aquired pneumonia. Med Clin North Am 2001;85:1427-40. http://dx.doi.org/10.1016/S0025-7125(05)70389

9. Brenner B, Kohn MS. The acute asthmatic patient in the ED: to admit or discharge. Am J Emerg Med 1998;16:69-75. http://dx.doi.org/10.1016/S07356757(98)90070-5

10. Naustdal T, Schanning J. Ear oximetry. Non-invasive monitoring of arterial oxygen. Tidskr Nor Lægeforen 1986;106:1592-3.

11. Celli BR. The Importance of Spirometry in COPD and Asthma. Chest 2000;117:15S-9S. http://dx.doi.org/10.1378/chest.117.2_suppl.15S

12. Melbye $\mathrm{H}$, Aaraas I, Fleten $\mathrm{N}$, et al. The value of $\mathrm{C}$-reactive protein testing in suspected lower respiratory tract infections. A study from general practice on the effect of a rapid test on antibiotic research and course of the disease in adults. Tidsskr Nor Lægeforen 1995;115:1610-15.

13. Clyne B, Olshaker J. The C-reactive protein. J Emerg Med 1999;17:1019-25. http://dx.doi.org/10.1016/50736-4679(99)00135-3

14. Eagan T, Gulsvik A, Mørkve O, et al. Hospital admissions due to obstructive lung diseases and pneumonia in two hospital districts. Tidsskr Nor Lægeforen 1999;119:4173-5.

15. Skaug K, Mørkve O, Gulsvik A. Immediate drug therapy of obstructive lung disease in hospital. Tidsskr Nor Lægeforen 2001;121:2115-18.

16. Fjellanger $R$, Brøgger JC, Eagan $T$, et al. Mortality after hospitalization for obstructive lung disease. Tidsskr Nor Lægeforen 2003;123:775-8.

17. Norges offisielle statistikk: Befolkningsstatistikk 1997 Hefte II, Statistisk Sentralbyrå, www.ssb.no.

18. Zaas D, Wise R, Wiener C. Airway obstruction is common but unsuspected in patients admitted to a general medicine service. Chest 2004;125:106-11. http://dx.doi.org/10.1378/chest.125.1.106

19. Global Initiative For Asthma - Global Strategy For Asthma Management And Prevention; National Institutes of Health; National Heart, Lung and Blood Institute, Revised 2002:76.

20. Global Initiative for Chronic Obstructive Lung Disease; Global strategy for the diagnosis, management, and prevention of chronic obstructive pulmonary disease NHLBI/WHO workshop report; National institutes of health; National Heart, Lung and Blood Institute, 2001:7.

21. Naalsund A, Vale JR. Clinical trial of an ear oxymeter. Tidsskr Nor Lægeforen 1986;106:759-60

22. Emerman C, Connors A, Lukens TW. Relationship between arterial blood gases and spirometry in acute exacerbations of chronic obstructive pulmonary disease. Ann Emerg Med 1989;18(5):523-7. http://dx.doi.org/10.1016/S01960644(89)80837-6

23. http://www.nice.org.uk/nicemedia/pdf/CG012quickrefguide.pdf

24. Malas O, Caglayan B, Fidan A, et al. Cardiac or pulmonary dyspnea in patients admitted to the emergency department. Respir Med 2003;97(12):1277-81. http://dx.doi.org/10.1016/j.rmed.2003.07.002

25. Lindenauer PK, Pekow P, Gay S, et al. Quality of care for patients hospitalized for acute exacerbations of chronic obstructive pulmonary disease. Ann Intern Med 2006;144:894-903.

26. Kolle S, Mørkve O. Diagnosis and treatment of obstructive lung diseases. Tidsskr Nor Lægeforen 1998;118:3268-71.

27. Rutschmann OT, Janssens JP, Vermeulen B, et al. Knowledge of guidelines for the management of COPD: a survey of primary care physicians. Respir Med 2004;98:932-7. http://dx.doi.org/10.1016/j.rmed.2004.03.018

28. White P. Spirometry and peak expiratory flow in the primary care management of COPD. Prim Care Respir J 2004;13(1):5-8. http://dx.doi.org/ 10.1016/j.pcrj.2003.11.009 